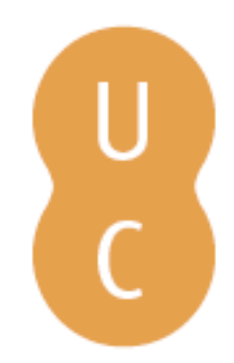

\title{
nommalina
}

\section{O greisen do depósito de caulino de S. Vicente de Pereira Jusã (Ovar): análise geoquímica da associação quartzomoscovite}
Autor(es):
Velho, José; Miranda, Alcina; Cerdeira, M.
Publicado por: Imprensa da Universidade de Coimbra; Laboratório de Radioactividade Natural da Universidade de Coimbra
persistente:
DOI: $\quad$ DOI:http://dx.doi.org/10.14195/978-989-26-1009-2_32
Accessed : $\quad$ 26-Apr-2023 16:29:44

A navegação consulta e descarregamento dos títulos inseridos nas Bibliotecas Digitais UC Digitalis, UC Pombalina e UC Impactum, pressupõem a aceitação plena e sem reservas dos Termos e Condições de Uso destas Bibliotecas Digitais, disponíveis em https://digitalis.uc.pt/pt-pt/termos.

Conforme exposto nos referidos Termos e Condições de Uso, o descarregamento de títulos de acesso restrito requer uma licença válida de autorização devendo o utilizador aceder ao(s) documento(s) a partir de um endereço de IP da instituição detentora da supramencionada licença.

Ao utilizador é apenas permitido o descarregamento para uso pessoal, pelo que o emprego do(s) título(s) descarregado(s) para outro fim, designadamente comercial, carece de autorização do respetivo autor ou editor da obra.

Na medida em que todas as obras da UC Digitalis se encontram protegidas pelo Código do Direito de Autor e Direitos Conexos e demais legislação aplicável, toda a cópia, parcial ou total, deste documento, nos casos em que é legalmente admitida, deverá conter ou fazer-se acompanhar por este aviso.

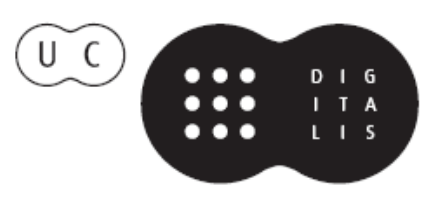




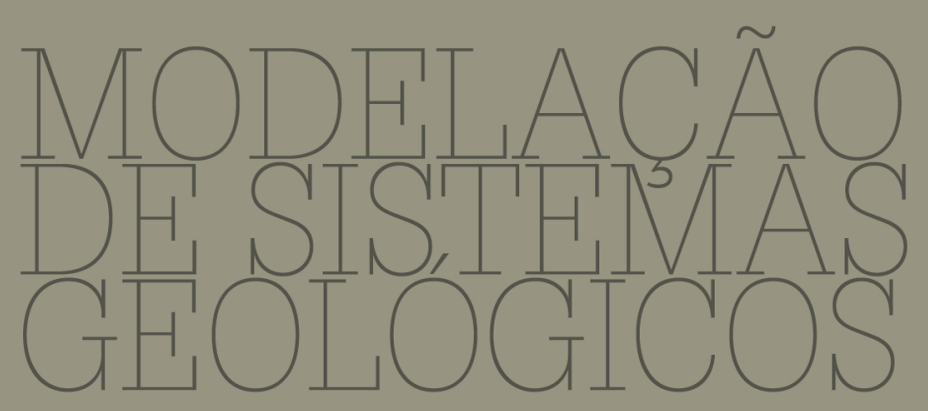

Homenagem ao Professor Doutor Manuel Maria Godinho

L.J.P.F. Neves, A.J.S.C. Pereira,

C.S.R. Gomes, L.C.G. Pereira,

A.O. TAVARES

IMPRENSA DA UNIVERSIDADE DE COIMBRA

CoImBra University Press 


\title{
MODELAÇÃO \\ DE SISTEMAS \\ GEOLÓGICOS
}

Homenagem ao Professor Manuel Maria Godinho

\section{O greisen do depósito de caulino de $S$. Vicente de Pereira Jusã (Ovar). Análise geoquímica da associação quartzo- moscovite}

\author{
José Velho'; Alcina Miranda ${ }^{1}$; M. Cerdeira ${ }^{1}$ \\ 1'Departamento de Geociências, Universidade de Aveiro, PORTUGAL, javelho@ua.pt
}

Palavras-chave: Greisenização, Moscovite, Caulino

\section{Resumo}

O depósito de caulino de S. Vicente de Pereira Jusã foi desenvolvido a partir de rochas migmatíticas condicionado por uma faixa de cisalhamento onde ocorreu deformação polifásica. A mineralogia do depósito é bastante complexa sendo evidentes dois estádios. Em primeiro lugar ocorreu um greisen onde se identificam as associações quartzomoscovite e quartzo-turmalina. Posteriormente a esta fase, ocorreu uma outra relacionada com a formação de caulinite. São evidentes fenómenos de silicificação, turmalinização e greisenização. Neste trabalho são apresentados os resultados relativamente à associação quartzo-moscovite. As amostras retiradas do greisen mostram teores elevados em $\mathrm{Al}_{2} \mathrm{O}_{3}$, $\mathrm{CaO}$ e perda ao rubro e menores teores em $\mathrm{FeO}, \mathrm{Na}_{2} \mathrm{O}, \mathrm{K}_{2} \mathrm{O}$ e $\mathrm{Li}_{2} \mathrm{O}$. Os valores mais elevados de ferro são provenientes das amostras da fácies pegmatítica enquanto as micas provenientes do greisen apresentam o valor mais baixo. Para além disso as moscovites do greisen apresentam valores baixos de B e de F. O modelo genético pressupõe ter havido um estádio inicial onde ocorreu um processo de albitização. Em seguida teria ocorrido uma circulação de uma fase fluida. $\mathrm{Na}$ altura da deformação sin- ou pós-D2, os fluidos caracterizavam-se quimicamente por actividades elevadas de $\mathrm{H}, \mathrm{B}, \mathrm{F}, \mathrm{Cl}$ e $\mathrm{Li}$, que modificaram os minerais presentes dando origem a associações mineralógicas do tipo quarto-mica e/ou quartzo-turmalina, que expressam um exogreisen.

Key-words: Greisenization, Mouscovite, Kaolin

\begin{abstract}
Kaolin deposit of S. Vicente de Pereira Jusã was developed from migmatitic rocks conditioned by a shear zone where a polyphasic deformation occurred. The mineralogy of the deposit is quiet complex where two stages can be identified. First, a greisen was formed identifying quartz-muscovite and quartz-tourmaline associations. After, occurred the formation of kaolinite. Silicification, turmalinization and greisenization phenomenon are evident. In this research only the results about quartz-muscovite assemblage are presented. Samples from the greisen show high contents in $\mathrm{Al}_{2} \mathrm{O}_{3}, \mathrm{CaO}$ and loss of ignition, and less
\end{abstract}


contents in $\mathrm{FeO}, \mathrm{Na}_{2} \mathrm{O}, \mathrm{K}_{2} \mathrm{O}$ and $\mathrm{Li}_{2} \mathrm{O}$. The higher contents in $\mathrm{Fe}$ are those from the pegmatitic facies while muscovite from the greisen show the lowest content. Besides this information, these muscovites show low contents in $B$ and $F$. The genetic model assumes an initial stage where an albitization process occurred. Then, a fluid phase followed. During sin or post $D 2$ variscan deformation, these fluids were characterized by high activities of $H$, $B, F, C l$ and $L i$ which modified the minerals present giving rise to mineralogical quartzmuscovite and quartz-tourmaline assemblages, which express an exogreisen.

\section{Introdução}

O depósito de caulino de S. Vicente de Pereira Jusã localiza-se na freguesia do mesmo nome, no lugar de Outeiro, concelho de Ovar. Geologicamente, faz parte da Zona de Ossa Morena (ZOM), constituída por formações metamórficas do Proterozóico Médio (micaxistos, gnaisses, migma-titos e gnaisses tonalíticos) e Superior (xistos porfiroblásticos, xistos cloríticos e moscovíticos, anfibolitos e vulcanitos ácidos). Três unidades litoestratigráficas foram identificadas no autócto-ne do bordo NW da ZOM, da base para o topo: Unidade de Lourosa, Unidade de Espinho e Uni-dade de Arada (Ribeiro et al., 1995). É na Unidade de Lourosa, caracterizada por metamorfismo de alto grau que ocorre o depósito de caulino de S. Vicente de Pereira Jusã, localizado mais concretamente no migmatito, isto é, no membro inferior da Unidade.

Ocorrem nesta unidade numerosos filões e injecções de granitóides de duas micas, atingindo-se a migmatização na parte central do antiforma de Vila da Feira. A migmatização é conside-rada contemporânea da fase D3 varisca (Ribeiro et al., 1995). Os afloramentos daqueles grani-tóides, denominados de ortognaisses graníticos, constituem maciços dispersos de dimensões relativamente pequenas, alongadas segundo a direcção da xistosidade, $\mathrm{N} 30^{\circ} \mathrm{W}$ (Aguado, 1992) (Figura 1). Pode-se definir uma pequena faixa com 1-2 km de largura média, por cerca de $25 \mathrm{~km}$ de extensão, em afloramentos descontínuos, por entre os xistos, desde Espinho até Adães. A maioria das intrusões graníticas encontra-se caulinizada e coberta por depósitos pliocénicos. Estas formações apresentam um estado de alteração superficial elevado que se encontram cobertas por numerosos depósitos de cobertura (altos níveis de praias antigas). São frequentes as intrusões de filões de quartzo com turmalina segundo direcções $\mathrm{N} 60-70^{\circ} \mathrm{E}$. $\mathrm{O}$ contacto com os xistos é franco e não se percebe qualquer auréola de metamorfismo. O depósito de caulino de S. Vicente de Pe-reira Jusã estende-se segundo um alinhamento NNW-SSE e é paralelo à falha que separa a Unidade de Lourosa da Unidade de Arada, tem, portanto, o mesmo 
alinhamento da Faixa Blastomilonítica e a sua extensão foi estimada cobrindo uma área de cerca de $11 \mathrm{~km}^{2}$ (Barbosa, 1988).

Neste depósito ocorrem paragéneses mineralógicas que traduzem, entre outros, um fenómeno de greisenização o que torna este depósito de grande interesse mineralógico. Bobos e Gomes (1998) analisaram não apenas o greisen mas também a alteração pós-greisen, responsável pela formação de caulinite. O objectivo deste trabalho é uma contribuição para um melhor conhecimento geoquímico do exogreisen expresso pelo fenómeno de metassomatismo que deu origem à associação quartzomoscovite, tentando interpretar a sequência de acontecimentos envolvidos.

\section{O greisen quartzo-moscovite}

Um greisen resulta de complexos processos metassomáticos tardios a posmagmáticos, que ocorrem no interior ou próximo de corpos graníticos consolidados e rochas adjacentes, sendo este processo precedido de metassomatismo alcalino durante o qual são produzidos os iões $\mathrm{H}^{+}$que iniciam o processo (Pirajno, 1992; Stemprok, 1987).

A geologia do depósito de caulino de S. Vicente de Pereira Jusã é relativamente complexa e, por vezes, de difícil interpretação e cartografia devido à actividade extractiva bem como à qualidade dos afloramentos. Em certas áreas do depósito ocorre uma associação típica de quartzo e mica, por vezes com turmalina, que traduz um greisen. As associações mais comuns são quartzo-mica e quartzo-mica-turmalina, relacionadas muitas vezes com zonas onde ocorrem veios de quartzo aos quais se encontra associada uma fácies mais pegmatítica. Na figura 2 representa-se em esquema um afloramento com o greisen que surge em diversas zonas do depósito com diferentes granulometrias. A mica encontra-se parcialmente caulinizada e tem uma cor característica amarela-esverdeada.

Foram analisadas diversas amostras de micas tendo-se utilizado para tal os métodos analí-ticos da Fluorescência de Raio X (FRX), para a determinação dos elementos maiores, excepto o $\mathrm{Na}$ e o $\mathrm{K}$ que foram avaliados por espectrofotometria de chama. O F foi avaliado pelo método dos eléctrodos selectivos, enquanto para o B foi usada a espectrofotometria de plasma acoplado induzido (ICP). Para os elementos menores foi usada a espectrofotometria de absorção atómica.

As micas analisadas foram provenientes do migmatito alterado por argilização (M1 e M2) sendo que a amostra M1 possui um grão mais fino que a amostra M2, da fácies pegmatítica (M3, M4, M5), com granulometrias diferentes por ordem crescente. Analisaram-se duas amostras de mica 
provenientes da fácies greisenizada (M6, M7) bem como de uma amostra do material mais caulinizado recolhida junto a uma fractura (M8). Sabe-se que a história da mica é complexa e diferentes gerações podem sobrepor-se espacialmente o que torna muito difícil o isolamento estrito de fases puras (Charoy, 1979). Na tabela 1 encontra-se representada a análise química das micas enquanto na tabela 2 são apresentados os resultados de $\mathrm{F}$ e de B, também naquelas micas.

Comparativamente com as restantes amostras, aquelas retiradas do

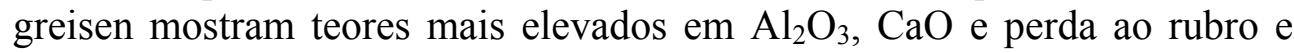
menores teores em $\mathrm{FeO}, \mathrm{Na}_{2} \mathrm{O}, \mathrm{K}_{2} \mathrm{O}$ e $\mathrm{Li}_{2} \mathrm{O}$, demonstrando que se está perante uma moscovite secundária formada, ao que tudo indica, a partir da plagioclase. Esta constatação mostra que o endogreisen já não se encontra presente no depósito estando-se perante o exogreisen, isto é, a fase posterior da alteração do greisen. Os valores mais elevados de ferro são provenientes das amostras da fácies pegmatítica (M3, M4, M5) enquanto as micas provenientes do greisen (M6 e M7) apresentam o valor mais baixo.

s $s \leqslant s$

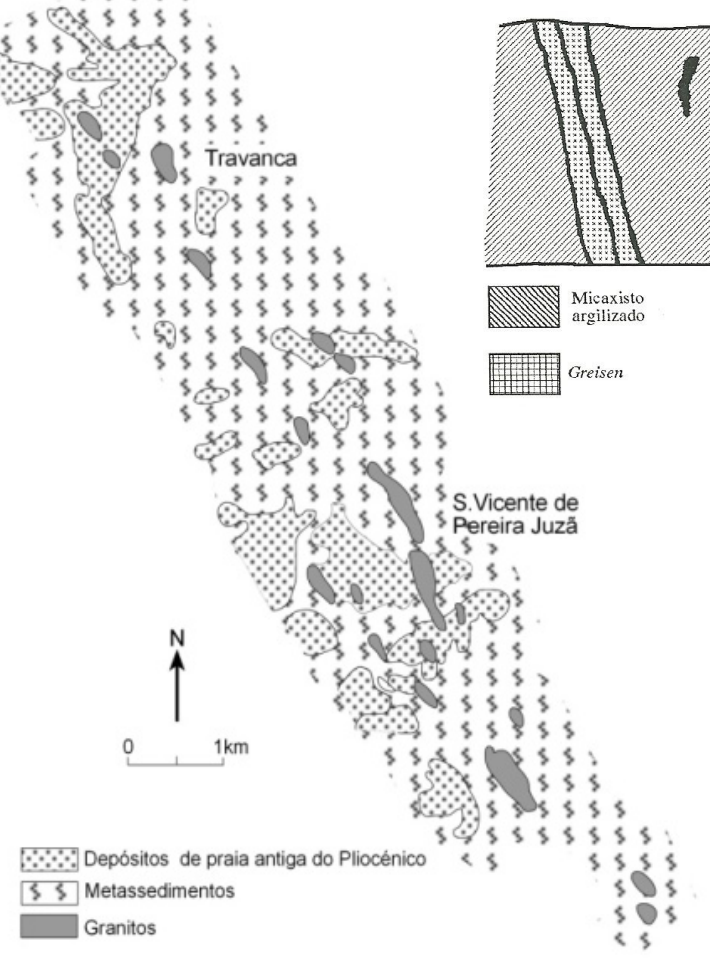

Figura 2. Representação esquemática do modo de afloramento do greisen. Escala: $1 \mathrm{~cm}=0,40$ metros.

Figura 1. Mapa geológico sintético da região envolvente do depósito de caulino de $\mathrm{S}$. Vicente Pereira de Jusã (adapt. Barbosa, 1988). 
Os teores em $\mathrm{B}$ e em $\mathrm{F}$ são muito baixos. O B parece possuir um comportamento inverso ao do $\mathrm{Li}$, bem identificado nas amostras provenientes do pegmatito se bem que se possa delimitar os diferentes domínios (Figura 3). Quanto ao F passa-se o oposto (Figura 4), havendo entre este elemento e o Li uma correlação positiva onde, mais uma vez, os diferentes domínios se encontram bem definidos.

Tabela 1. Resultados da análise química nas micas de diferentes proveniências (valores em \%).

\begin{tabular}{lccccccccccccc}
\hline Ref & $\mathrm{SiO}_{2}$ & $\mathrm{Al}_{2} \mathrm{O}_{3}$ & $\mathrm{TiO}_{2}$ & $\mathrm{FeO}$ & $\mathrm{Fe}_{2} \mathrm{O}_{3}$ & $\mathrm{MnO}$ & $\mathrm{MgO}$ & $\mathrm{CaO}$ & $\mathrm{Na}_{2} \mathrm{O}$ & $\mathrm{K}_{\mathbf{2}} \mathrm{O}$ & $\mathrm{Li}_{2} \mathrm{O}$ & P.R. & Total \\
\hline $\mathrm{M} 1$ & 50,89 & 29,97 & 1,08 & 0,60 & 0,31 & 0,02 & 0,43 & 0,17 & 0,42 & 9,77 & 0,30 & 6,02 & 99,98 \\
$\mathrm{M} 2$ & 50,95 & 33,34 & 0,15 & 0,70 & 0,31 & 0,02 & 0,12 & 0,14 & 0,90 & 8,98 & 0,06 & 4,60 & 100,09 \\
$\mathrm{M} 3$ & 46,30 & 34,78 & 0,09 & 1,61 & 0,80 & 0,01 & 0,04 & 0,17 & 0,60 & 9,14 & 1,05 & 5,23 & 100,02 \\
$\mathrm{M} 4$ & 45,05 & 34,10 & 0,08 & 1,91 & 0,88 & 0,05 & 0,09 & 0,18 & 0,80 & 11,00 & 0,82 & 5,09 & 100,05 \\
$\mathrm{M} 5$ & 44,62 & 34,75 & -- & 1,91 & 0,82 & 0,04 & -- & 0,18 & 0,59 & 10,81 & 1,02 & 5,27 & 100,01 \\
$\mathrm{M} 6$ & 45,23 & 37,25 & 0,24 & 0,51 & 0,21 & 0,03 & 0,21 & 0,19 & 0,16 & 7,98 & 0,02 & 7,77 & 99,80 \\
$\mathrm{M} 7$ & 45,66 & 37,12 & 0,02 & 0,48 & 0,28 & 0,06 & 0,24 & 0,15 & 0,18 & 8,48 & 0,06 & 7,22 & 99,95 \\
$\mathrm{M} 8$ & 46,69 & 35,89 & 0,33 & 0,53 & 0,23 & 0,05 & 0,09 & 0,19 & 0,37 & 6,94 & 0,06 & 8,70 & 100,07 \\
\hline
\end{tabular}

\begin{tabular}{lcccccccc} 
& \multicolumn{7}{c}{ Número de iões na base de 24 (O,OH) } \\
& M1 & M2 & M3 & M4 & M5 & M6 & M7 & M8 \\
$\mathrm{Si}$ & 6,764 & 6,631 & 6,153 & 6,076 & 5,998 & 6,105 & 6,121 & 6,309 \\
${ }^{\mathrm{IV}} \mathrm{Al}$ & 1,236 & 1,369 & 1,847 & 1,924 & 2,002 & 1,895 & 1,879 & 1,691 \\
$\mathrm{~V} \mathrm{Al}$ & 3,458 & 3,745 & 3,593 & 3,497 & 3,536 & 4,029 & 3,986 & 3,993 \\
$\mathrm{Fe}^{2+}$ & 0,067 & 0,076 & 0,200 & 0,217 & 0,218 & 0,057 & 0,077 & 0,060 \\
$\mathrm{Fe}^{3+}$ & 0,030 & 0,030 & 0,089 & 0,089 & 0,094 & 0,021 & 0,029 & 0,006 \\
$\mathrm{Mg}$ & 0,086 & 0,232 & 0,016 & 0,002 & 0,004 & 0,041 & 0,048 & 0,028 \\
$\mathrm{Mn}$ & 0,002 & 0,022 & 0,005 & 0,006 & 0,009 & 0,032 & 0,007 & 0,018 \\
$\mathrm{Ti}$ & 0,108 & 0,015 & 0,009 & 0,008 & -- & 0,002 & 0,002 & 0,034 \\
$\mathrm{Ca}$ & 0,024 & 0,014 & 0,016 & 0,052 & 0,052 & 0,049 & 0,022 & 0,028 \\
$\mathrm{Na}$ & 0,112 & 0,202 & 0,189 & 0,209 & 0,210 & 0,048 & 0,047 & 0,097 \\
$\mathrm{~K}$ & 1,656 & 1,484 & 1,543 & 1,893 & 1,857 & 1,378 & 1,450 & 1,202 \\
$\mathrm{Li}$ & 0,214 & 0,031 & 0,558 & 0,499 & 0,551 & 0,011 & 0,032 & 0,033 \\
\hline
\end{tabular}

O Li possui um papel importante, senão mesmo preponderante, ao nível das micas, ao longo dos processos metassomáticos posmagmáticos. As fácies pegmatíticas representam termos das séries evolutivas graníticas originados a partir do magma residual rico em gases que pode ter concentrações de elementos voláteis como Li, F, B, Cl, entre outros. É natural, portanto, que as fases minerais que as constituem (neste caso a 
mica), apresentem teores mais elevados desses elementos do que as que se formaram noutras condições.

Charoy (1979) havia mostrado que a greisenização desenvolve fases micáceas fortemente aluminosas não litiníferas. Ao longo da greisenização a actividade do lítio ao nível das fases micáceas começará por aumentar, para diminuir fortemente nas fases posteriores. Os resultados mostram que o teor em Li é baixo.

Tabela 2. Teores de F e de B nas micas (valores em ppm).

\begin{tabular}{ccccccc}
\hline Elemento & M1 & M3 & M4 & M5 & M6 & M7 \\
\hline B & 3,20 & 1,91 & 1,24 & 1,43 & 2,57 & 2,48 \\
F & 1,47 & 2,31 & 2,34 & 2,45 & 0,27 & 0,34 \\
\hline
\end{tabular}

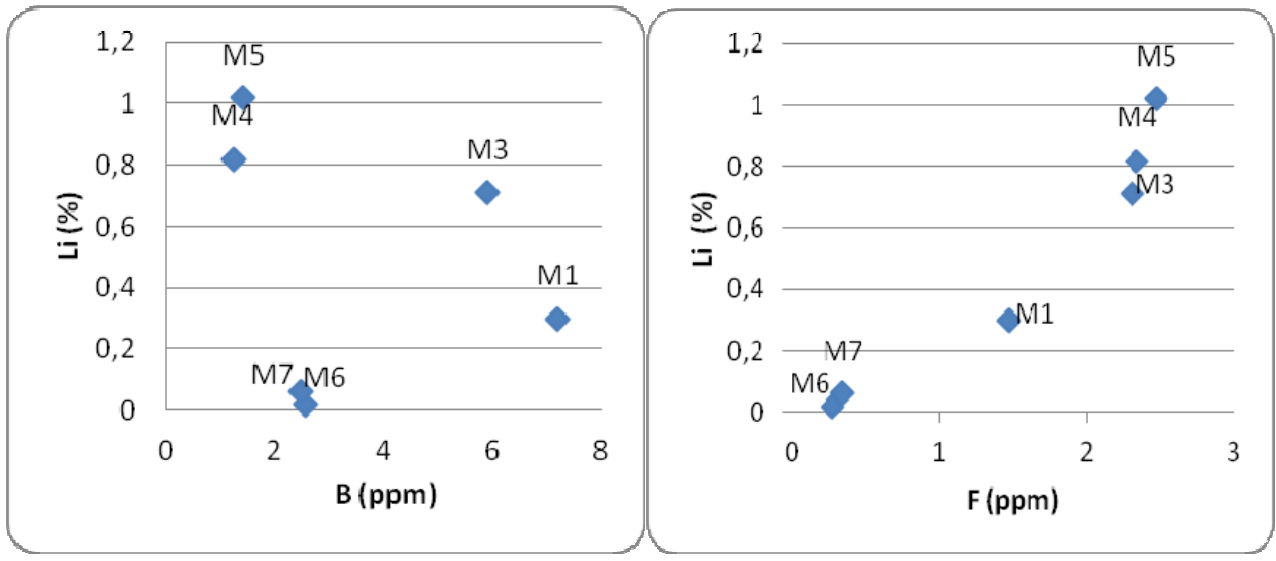

Figura 3. Relação entre os teores de B e Figura 4. Relação entre os dados de F de Li. e de Li.

Os valores mais elevados de $\mathrm{Li}_{2} \mathrm{O}$ registam-se nas micas da fácies pegmatítica enquanto o valor mais baixo ocorre na mica do greisen. $\mathrm{O}$ facto dos teores em F, observados nas micas do greisen, serem baixos, está de acordo com os dados de Fernandez (1991) que defende que, apesar deste elemento ter um papel relevante no processo de greisenização, este não se fixa na(s) fase(s) mineral(is) neoformada(s), concentrando-se na fase fluida hidrotermal. 


\section{Rocha total}

Devido à impossibilidade de se conseguir recolher amostras sãs da rocha granítica torna-se inviável fazer-se um balanço geoquímico. A rocha sã não aflora no local em estudo nem tão pouco nas imediações do depósito. $\mathrm{O}$ estudo foi feito tendo apenas em vista tirar algumas ilações quanto à evolução geoquímica do processo de greisenização.

As análises químicas foram realizadas em amostras correspondentes a dois estádios de alteração distintos. Uma das amostras (A), traduz uma alteração precoce da rocha-mãe. A textura gnaissóide é ainda visível e a respectiva granularidade é fina a média. Os feldspatos apresentam efeitos de caulinização, facto que confere à rocha notável friabilidade. Uma segunda amostra foi estudada (B) que corresponde a um estádio mais evoluído da greisenização, caracterizado por granularidade média a fina. A degradação das amostras em termos texturais não permitiu a execução de lâminas delgadas para a realização do estudo petrográfico, restando, por isso, a análise química como meio de as caracterizar. Os resultados dessa análise encontram-se representados nas tabelas 3 e 4, no que diz respeito aos elementos maiores e aos elementos em traço, respectivamente.

Tabela 3. Resultados da análise química de elementos maiores (valores em \%) efectuada sobre a rocha total, variando segundo o grau de alteração

$\begin{array}{cccccccccccccc}\text { Ref. } & \mathrm{SiO}_{2} & \mathrm{Al}_{2} \mathrm{O}_{3} & \mathrm{TiO}_{2} & \mathrm{FeO} & \mathrm{Fe}_{2} \mathrm{O}_{3} & \mathrm{MnO} & \mathrm{MgO} & \mathrm{CaO} & \mathrm{Na}_{2} \mathrm{O} & \mathbf{K}_{2} \mathrm{O} & \mathrm{Li}_{2} \mathrm{O} & \text { P.R. } & \text { Total } \\ \text { A } & 69,47 & 19,75 & 0,26 & 1,00 & 0,40 & --- & 0,31 & 0,10 & 1,29 & 2,11 & 0,12 & 5,90 & 100,71 \\ \text { B } & 69,94 & 22,16 & ---- & 0,10 & 0,05 & --- & 0,11 & 0,07 & 0,02 & 2,22 & 0,02 & 5,35 & 100,04\end{array}$

Tabela 4. Resultados da análise química de elementos traço (valores em ppm) correspondentes a rocha total

\begin{tabular}{llllllllllllll}
\hline Ref. & Ba & Zr & Nb & Y & Th & V & Zn & Cu & Ni & Pb & Rb & Sr & Cr \\
\hline A & 471 & 141 & 8 & 39 & -- & 22 & 70 & 11 & 6 & 69 & 158 & 70 & 14 \\
B & 59 & 39 & 15 & 108 & -- & 5 & 28 & 18 & 7 & 31 & 172 & -- & 8 \\
\hline
\end{tabular}

Ao considerarmos as análises de elementos maiores efectuadas na rocha total, correspondentes ao estádio inicial de alteração da rocha original bem como à fácies greisenizada, verifica-se um aumento do teor de $\mathrm{Al}_{2} \mathrm{O}_{3}$, para além de uma descida acentuada de $\mathrm{Na}_{2} \mathrm{O}$ e de Fe quando se passa de um estádio para o outro. $\mathrm{O}$ Mn não foi detectado em nenhuma das fácies e o $\mathrm{Li}$ apresenta um valor muito mais baixo na fácies greisenizada, o que vem de encontro às conclusões de diversos autores, por exemplo, Charoy (1979). 
A variação do Li é idêntica na rocha total e na mica correspondente. A análise do lítio na mica do greisen tinha mostrado um valor muito baixo, enquanto o teor em Li na mica da amostra que representa o estádio mais precoce de alteração é muito superior. Segundo Charoy (1975), é essencialmente a evolução química da fase micácea a responsável pelo aumento dos teores em Li observados nas rochas ao longo dos processos de evolução granítica, podendo os dados referidos relacionarem-se com este facto.

Quanto aos elementos traço, o facto de não se possuir análise química da rocha sã limita a interpretação dos resultados. No greisen, verifica-se um aumento de $\mathrm{Rb}$ e de $\mathrm{Y}$ bem como pequenos aumentos nos teores de $\mathrm{Nb}$ e de $\mathrm{Cu}$. Não foi possível saber se as descidas verificadas em relação aos teores dos restantes elementos traço foi contínua ou se foi precedida de uma subida inicial relativamente à rocha sã.

\section{Evolução da greisenização}

$\mathrm{O}$ ambiente estrutural surge como um elemento determinante quanto à expressão dos fenómenos hidrotermais e ao seu prosseguimento em grande escala, para além da história tectónica e estrutural da zona onde o depósito se localiza. As estruturas regionais resultaram de uma deformação varisca polifásica, identificando-se quatro fases de deformação (Aguado, 1992).

As primeiras três são consideradas como sendo ante-Vestefaliano Médio enquanto a última será pós-Estefaniano Inferior. A actividade hidrotermal estará relacionada com um sistema deformacional que funcionou como canal de circulação de fluidos relacionados genética e espacialmente com intrusões granitóides ou com fluidos de origem metamórfica ou crustal. Nos estádios mais tardios, as águas meteóricas terão tido um papel relevante no desenvolvimento da caulinização, assunto que se encontra fora do âmbito deste trabalho.

A greisenização evidencia-se pela associação quartzo-mica (fina e amarela esverdeada), havendo locais onde a mica é o componente principal e outros em que o greisen é mais rico em quartzo-turmalina. Este fenómeno reflecte a alteração posmagmática de uma rocha primária granitóide, pela acção de soluções enriquecidas em voláteis, associadas ao processo de arrefecimento de intrusões graníticas.

Neste fenómeno de greisenização distinguimos entre endogreisen e exogreisen. No primeiro caso, podemos considerar ter havido um estádio inicial relacionado com um ambiente fechado onde ocorreu um processo de albitização. Mas, com o tempo, o sistema abre-se com a circulação de uma 
fase fluida desequilibrada em relação à paragénese existente. Na altura da deformação sin- ou pós-D2, os fluidos caracterizavam-se quimicamente por actividades elevadas de $\mathrm{H}, \mathrm{B}, \mathrm{F}, \mathrm{Cl}$ e $\mathrm{Li}$, que modificaram os minerais presentes dando origem a associações mineralógicas do tipo quarto-mica e/ou quartzo-turmalina, que expressam um exogreisen.

A este primeiro estádio caracterizado por uma sequência de eventos relacionados com a greisenização, terá ocorrido um segundo, caracterizado pela alteração pós-greisenização que inclui a caulinização (alteração supergénica) onde se formou caulinite estruturalmente desordenada para além de haloisite.

\section{Conclusões}

A contribuição deutérica para a caulinização e formação do depósito de caulino de S. Vicente de Pereira Jusã é apoiada pelos fenómenos de greisenização, de silicificação e de turmalinização de intervenção reconhecida no local. Esta estreita relação entre fenómenos de carácter tipicamente hidrotermal e a caulinização com uma extensão importante, não é, portanto, fortuita. A alteração deutérica, pela intensa fracturação que exige e pela instabilidade dos minerais que desenvolve, constituiu o factor indispensável e promotor do desenvolvimento de caulinização supergénica que se sobrepôs posteriormente. Neste trabalho foi apenas evidenciada a greisenização através da formação da associação quartzo-moscovite. As paragéneses identificadas, as análises químicas realizadas e os dados de campo mostram que se está perante um exogreisen.

\section{Bibliografia}

Aguado V. (1992) - Geologia estructural de la Zona de cizalla Porto-Tomar en la región de Oliveira de Azeméis - Serra de Arada (Norte de Portugal) Tese de Doutoramento, Universidade de Aveiro, Aveiro.

Barbosa B. (1988) - Origem e idade dos caulinos portugueses em granitos. Boletim da Sociedade Geológica de Portugal; 24, 101-105.

Bobos I, Gomes C. (1998) - Greisen and post-greisen alteration in the São Vicente de Pereira kaolinite deposit, Portugal. The Canadian Mineralogist; 36, 1615-1624.

Charoy, B. (1979) - Définition et importance dês phénomènes deutériques et des fluids associés dans le granite - Conséquences métallogéniques. Sciences de la Terre, Série "Mémoires", 37.

Charoy, B. (1975) - Ploemeur kaolin deposit (Brittany): na example of hydrothermal alteration. Petrologie; I (4), 253-266.

Fernandez, A. (1991) - Petrologia granítica del pluton de Caldas de reyes (Pontevedra, España) Estructura, mineralogia, geoquímica y petrogenesis. Tesis Doctoral, Ediciós Do Castro, Série Nova Terra, $\mathrm{n}^{\circ} 5$, Madrid.

Pirajno F. (1992) - Hydrothermal Mineral Deposit, Springer Verlag, New York. 
Ribeiro A, Pereira E, Chaminé H, Rodrigues J. (2005) - Tectónica do megadomínio de cisalhamento entre a Zona de Ossa Morena e a Zona Centro Ibérica na região de Porto-Lousã. Livro de Actas IV Congresso Nacional de Geologia, Universidade do Porto; 4, 329-333.

Stemprok M. (1987) - Greisenisation. A review. Geol. Rundsch; 76, 169-175. 